\title{
Food beliefs and practices among the Kalenjin pregnant women in rural Uasin Gishu County, Kenya
}

\author{
Roselyter Monchari Riang' $a^{1,2^{*}}$, Jacqueline Broerse ${ }^{2}$ and Anne Kisaka Nangulu ${ }^{1,3}$
}

\begin{abstract}
Background: Understanding food beliefs and practices is critical to the development of dietary recommendations, nutritional programmes, and educational messages. This study aimed to understand the pregnancy food beliefs and practices and the underlying reasons for these among the contemporary rural Kalenjin communities of Uasin Gishu County, Kenya.

Methods: Through semi-structured interviews, data was collected from 154 pregnant and post-natal Kalenjin women about restricted and recommended foods, and why they are restricted or recommended during pregnancy. Respondents were purposively selected (based on diversity) from those attending Maternal and Child Health (MCH) care in 23 rural public health facilities. Key informant interviews $(n=9)$ with traditional Birth Attendants (TBA) who were also herbalists, community health workers, and nursing officers in charge of MCH were also conducted. Quantitative data was analysed using SPSS software. Data from respondents who gave consent to be tape recorded $(n=42)$ was transcribed and qualitatively analysed using MAXQDA software.
\end{abstract}

Results: The restriction of animal organs specifically the tongue, heart, udder and male reproductive organs, meat and eggs, and the recommendation of traditional green vegetables and milk was reported by more than $60 \%$ of the respondents. Recommendation of fruits, traditional herbs, ugali (a dish made of maize flour, millet flour, or Sorghum flour, sometimes mixed with cassava flour), porridge and liver, and restriction of avocadoes and oily food were reported by more than $20 \%$ of the respondents. The reasons for observing these dietary precautions were mainly fears of: big foetuses, less blood, lack of strength during birth, miscarriages or stillbirths, and maternal deaths as well as child's colic and poor skin conditions after birth.

Conclusion: Pregnancy food beliefs were widely known and practised mainly to protect the health of the mother and child, and ensuring successful pregnancy outcome. Given the deep-rooted nature of the beliefs, it is advisable that when nutritious foods are restricted, nutritional interventions should rather search for alternative sources of nutrition which are available and considered to be appropriate for pregnancy. On the other hand, nutritional advice that does not address these health concerns and assumptions that underlie successful pregnancy and delivery is unlikely to be effective.

Keywords: Food beliefs, Taboos, Maternal and child health, Nutritional interventions, Pregnancy complications, Kalenjin, Kenya

\footnotetext{
* Correspondence: monchari2002@yahoo.com; r.m.rianga@vu.nl

${ }^{1}$ Moi University, School of Arts and Social Sciences, P.O. Box 3900-30100,

Eldoret, Kenya

${ }^{2}$ Athena Institute, Faculty of Earth and Life Sciences, VU University

Amsterdam, De Boelelaan 1085, 1081 HV Amsterdam, The Netherlands

Full list of author information is available at the end of the article
} 


\section{Background}

Undernutrition is a serious global health problem which has not yet been sufficiently addressed. Approximately 795 million people are undernourished, mostly Low and Middle-Income Countries (LMICs) [1]. Nutrition is most critical during pregnancy because poor nutrition puts both mother and baby at risk. Poorly nourished expectant mothers are at a higher risk of having a preterm birth, and giving birth to babies with low birth-weight and Intra Uterine Growth Restrictions (IUGR); while also facing multiple threats to their own health and survival [2, 3]. Babies born underweight, pre-term or with IUGR have increased risk of neonatal death. A number of those who survive these conditions may develop into stunted adults who will, in turn, give birth to stunted children, representing a vicious cycle of nutritional problems [4]. Nearly half (45\%) of global deaths among children under five are attributed to undernutrition, amounting to 3 million deaths each year [5]. In Kenya, 35\% of children under five have been found to be stunted with higher levels of stunting in rural areas [6]. Furthermore, $56 \%$ of infant deaths in Kenya occur during the first month of life and $5 \%$ of children do not survive to the age of 5 years [7].

In LMICs, socio-economic factors (especially consumer income) have been associated with inadequate nutritional status and household food security [8-10]. However, a study undertaken in Ethiopia established that some of the highest prevalence rates of malnutrition were found in the food-surplus regions of the country, indicating that food availability is only one component of food security and that it does not necessarily ensure adequate nutritional status [11]. Similarly in Kenya, although $89 \%$ of land is arid and semi-arid [12], even the arable regions still experience nutritional deficiencies. Uasin Gishu County for instance, where this study was conducted, has climatic conditions and soil type which are generally suitable for livestock keeping and food crop production with an average rural land holding of 5 hectares, hence it is commonly known as the country's food basket [13]. However, the nutritional status of Uasin Gishu County is worse than the national norm. Some $11.5 \%$ of the Uasin Gishu population is underweight compared to the national level $(11.0 \%)$ while $31.2 \%$ of children are stunted compared to $26.0 \%$ nationally [7].

The UN Children's Fund (UNICEF) Food-Care Health conceptual framework lists cultural norms, taboos and beliefs as one factor that may cause malnutrition [14]. Meyer-Rochow [15] for instance, established that food items within a given ecological zone may be considered inedible due to "nutritional taboos." Food beliefs and taboos are a global phenomenon that are intended to have a positive effect to the practising community including: conservation of a scarce or sacred resource
$[15,16]$, maintenance of social norms, morals, group cohesion and identity [17] and protection of human health $[18,19]$. Food taboos and restrictions are particularly strictly observed during pregnancy as pregnant women are considered to be more vulnerable and hence what they eat must be regulated to protect the foetus and reduce the occurrence of complicated labour and delivery [19-25]. Other studies, however, indicate that failure to make use of available food resources in a given ecological zone due to taboos and beliefs is one of the major causes of malnutrition [26, 27]. This indicates that more research needs to be carried out on this crucial area.

In Kenya, only a few studies have concentrated on the nexus between pregnancy, culture and nutrition. Boerma and Mati [28] and Oniango and Komokoti [29] are among the few that have researched this subject. They established that pregnant women are restricted from eating certain food items such as liver, intestines, kidney, milk, sweet potatoes, sugar, salt, eggs and bananas because these foods are believed to cause obstructed labour. The same norms, however, encourage pregnant women to take certain food items such as cow's blood, sour milk and lots of water, and to vomit following a heavy meal. These norms are designed to keep the baby small at birth and thus ensure safe delivery for both mother and baby.

This clearly indicates the existence of food beliefs related to pregnancy in Kenya. There are 42 ethnic groups in Kenya with varying and changing nutritional traditions and taboos which indicates the need to develop an elaborate body of knowledge concerning diverse cultural dietary practices during pregnancy as a basis for contextualised understanding and effective interventions. This is a particularly important issue in areas with high levels of child stunting, such as the area under study. Lack of appropriate knowledge on culturally prescribed nutritional taboos and beliefs can have a powerful impact on the outcome of malnutrition relief efforts or prevention campaigns and interventions [20]. This study investigates food belief practices among the contemporary Kalenjin community of rural Uasin Gishu County. The specific objectives were to investigate the various food beliefs during pregnancy, and examine the underlying reasons. The findings of this study will provide a basis for developing culturally appropriate nutritional interventions and empowerment programmes with a view to providing effective nutritional counselling targeting pregnant women. This may improve birth outcomes and long-term quality of life.

\section{Methods}

Theoretical framework (symbolic interactionist theory (SIT)) The research findings of this study were interpreted and understood through the symbolic interactionist perspective as expounded by Messer [30]. Symbolic interaction 
theory (SIT) is a frame of reference for how people act toward things based on the meaning those things have for them, and these meanings are derived from social interaction and modified through interpretation [31]. Messer (1989) classified food according to a number of symbolic dimensions which are culturally constructed in the process of social interaction and this influences human food selection. Having no biological base, these social constructs of nutrition are based on what people believe to be true about food and not just on what is objectively true. So, the symbolic meaning of food overrides those actual biological facts regarding diet and health. These may be the dimensions most prominent in the food proscriptions and prescriptions of nutritionally "vulnerable groups" such as infants, children, and pregnant and lactating women. Messer [30] found that while people shared the same general structure and rules for classification, they did not necessarily judge all items equivalently, given the differences in individual experience. Also, individuals differed in the extent to which they had acquired information and applied it to their own diets and health. Understanding these food symbolic dimensions therefore can greatly aid in interpretation of food habits that might be beneficial or harmful to a particular population or subpopulation.

Messer [30] classified food into eight cultural symbolic dimensions including: hot-cold, health, age, gender, illness, rituals and economic status. These symbolic classifications influence food selection, food preferences, and dietary intakes. In this study, we adopted these symbolic classifications as guiding principles in the analysis of the research findings. However, hot-cold and economic status factors were excluded because they were not established in this study. On the other hand, symbolic classfication of food as "traditional" or "cultural" and "dirty food" emerged in the study and these were included in the model.

\section{Description of the research setting}

This study was conducted in Uasin Gishu County in Kenya. Uasin Gishu County is one of the 47 counties of Kenya and is geographically located in the western part of the country. It has its headquarters in Eldoret town. The county is divided into six sub-counties and it covers a total area of $3,345.2 \mathrm{~km} 2$ with a total estimated population of $1,023,656$, comprising $50 \%$ male and $50 \%$ female [32]. The predominant settlement pattern is rural (64.1\%). There are 171 health facilities in the county, of which 90 are public [32]. Most of the facilities are concentrated within Eldoret Municipality. The climatic conditions and soil type in this region are generally favourable for a wide range of livestock and crop production.
The Kalenjin are the predominant ethnic population in Uasin Gishu County. This ethnic group is composed of smaller subtribes: the Kipsigis, Nandi, Tugen, Keiyo, Marakwet, Pokot also called the Suk, Sabaot and the Terik. The ethnic group has its own mother tongue. However the sub-tribes speak their own dialect. The Nandi have the highest settlement in the county, followed by the Keiyo [13]. The Kalenjin had been seminomadic pastoralists of long standing. They had been raising cattle, sheep and goats and cultivating sorghum and pearl millet since at least the last millennium B.C. The Kalenjin have a common staple diet: Kimyet (ugali) (a paste of cooked maize or millet flour sometimes mixed with sorghum flour), native vegetables and mursik (sour milk mixed with charcoal dust, sometimes mixed with cow's blood), supplemented with roast meat (usually beef or goat). Fish was also part of the traditional diet though largely limited to residents bordering the lake region community. Childbirth among the Kalenjin was exclusively women's concerns from which men were excluded. After delivery, women were considered unclean as a result they were secluded for a certain period of time during which, their movement was restricted to a given point within the household and were fed on special diet until the cleansing rite was performed.

\section{Data collection}

Semi-structured and key informant interviews were used for data collection in 23 rural health facilities selected from the six sub-counties of Uasin Gishu County between April and August 2015. Uasin Gishu County was purposively selected because this study is part of a broader project in the County on maternal and child nutritional health. The main factor considered in selecting the health facilities is that they must be in the rural area and have their population mainly composed of the Kalenjin clients, and be spatially distributed from each other to diversify responses.

\section{Interviews with pregnant and post-natal women}

Pregnant and post-natal Kalenjin women who came for routine antenatal and child welfare check-ups in the Maternal and Child Health $(\mathrm{MCH})$ section in the rural health facilities were included in the study, based on availability and willingness to participate [33]. A combination of closed and open questions were used to investigate women's subjective experience of pregnancy and nutrition [34]. The women were individually interviewed face to face in a private room at the health facility to give the opportunity to observe their facial expressions and body language, particularly important for correct interpretation of the answers [35]. Each woman was interviewed once by the first author and two female research assistants. The research assistants were well trained to 
ensure consistency and to ensure inter-researcher reliability. The interview guide was originally written in English but was translated into Swahili and into the local Kalenjin language where necessary. The local language interviews were conducted by the research assistants because they could speak and understand the language. The researchers obtained written informed consent before commencing with data collection. Respondents were asked about the following main issues: food that is restricted or recommended during pregnancy, and the underlying reasons, opinions on the beliefs and who gave the advice. Respondents' social demographic characteristics were also captured. Each interview lasted for 25-90 min. None of the respondents pulled out of the interview before completion.

The data collection exercise was continued until saturation was reached [36] at a sample size of 154 responses. Out of the 154 respondents, only 42 gave consent to be audio taped; these 42 respondents provide the direct quotations in the results section. Most respondents feared to be audio-recorded, probably because many audio recorded witnesses to the 2007 post-election violence died mysteriously. As a result, for the other 112 respondents, extensive note taking was preferred to create a more relaxed interview setting and encourage full disclosure [36]. Demographic characteristics of these respondents are presented in Table 1 below.

Out of the 154 respondents, 62 were antenatal clients (ANC) and 82 post-natal clients (PNC) who had children younger than one year old. Various sub-ethnic groups of the Kalenjin were represented: the Nandi were the majority $(71 \%)$ followed by the Keiyo (18\%), the Marakwet (5\%), and the Kipsigis (3\%). The Nandi have the highest population in Uasin Gishu County followed by the Keiyo and the Marakwet [37]. There were two Tugen respondents, while Terik and Pokot were represented by one respondent each. The age of the respondents ranged from 18 to 42 years, with the majority of the respondents (61\%) ranging between 20 and 29 years old. More than half (58\%) of the respondents work in the domestic informal sector as either subsistence farmers or housewives. Most of them (88\%) had not received more than secondary education. Most women were married $(71 \%)$, while $18 \%$ were unmarried. Of the women who were unmarried, $50 \%$ were either pupils or students. $28 \%$ of the respondents were gravida 1 .

\section{Key informant interviews}

In-depth key informant interviews were conducted with Traditional Birth Attendants (TBAs) who were also traditional pregnancy herbalists $(n=6)$, community health workers $(n=2)$, and the nursing officer in charge of $\mathrm{MCH}(n=1)$. The nursing officer and the community health workers were selected from one of the largest
Table 1 Demographic Characteristics of Respondents

\begin{tabular}{|c|c|c|}
\hline Characteristic & Categories & $\begin{array}{l}\text { Percentage } \\
(N=154)\end{array}$ \\
\hline \multirow[t]{2}{*}{ Maternal status } & Antenatal mothers & 40 \\
\hline & Post-natal mothers & 60 \\
\hline \multirow[t]{2}{*}{ Gravidity } & First pregnancy/child & 28 \\
\hline & More than one pregnancy & 72 \\
\hline \multirow[t]{5}{*}{ Age (years) } & $\leq 19$ & 9 \\
\hline & $20-24$ & 29 \\
\hline & $25-29$ & 32 \\
\hline & $30-34$ & 18 \\
\hline & $\geq 35$ & 12 \\
\hline \multirow[t]{4}{*}{ Marital status } & Never married & 18 \\
\hline & Currently married & 77 \\
\hline & Separated & 3 \\
\hline & Widowed & 2 \\
\hline \multirow[t]{3}{*}{ Educational level } & Primary education & 54 \\
\hline & Secondary education & 34 \\
\hline & Post-secondary education & 12 \\
\hline \multirow[t]{6}{*}{ Occupation } & Farming & 40 \\
\hline & Business & 21 \\
\hline & Housewife & 18 \\
\hline & Formal employment & 9 \\
\hline & Student/pupil & 8 \\
\hline & Others & 4 \\
\hline \multirow[t]{7}{*}{ Ethnic Affiliation } & Nandi & 71 \\
\hline & Keiyo & 18 \\
\hline & Marakwet & 5 \\
\hline & Kipsigis & 3 \\
\hline & Tugen & 1 \\
\hline & Terik & 1 \\
\hline & Pokot & 1 \\
\hline
\end{tabular}

facilities because they are likely to encounter a wide range of pregnancy nutritional experiences and challenges given their large catchment area. The TBAs were identified by snowball and convenient sampling through respondents who gave birth at home and who took herbal remedies during pregnancy. The TBAs were interviewed at their practise, either in their homes or market centres. Information gathered from key informants was employed to explore meanings and enrich the responses obtained from respondent interviewees. Key informants were interviewed about the following main issues: perceived restricted and recommended foods; in-depth information on underlying reasons for these recommendations; and their food advice to pregnant women. Each interview took $85-100 \mathrm{~min}$. The key informants, particularly the TBAs, accompanied the researcher to the gardens to 
identify the food crops that were mentioned in the study, giving them their local names. The identified crops and animals were then photographed and collected for proper scientific identification and classification in consultation with the plant taxonomists at the University of Nairobi herbarium and the National Museums of Kenya

\section{Data processing and analysis}

Forty-two interviewees and most key informants (except the $\mathrm{MCH}$ nursing officers and community health workers) consented to being tape-recorded. The Swahili tapes were transcribed in English by the first author while the Kalenjin tapes were transcribed by a Kalenjin speaking transcriber. For the other respondents, extensive note taking took place. The transcripts and notes were coded and categorised in themes using the software for handling qualitative data MAXQDA (version 12.1.3) with each participant identified by a pseudonym. The pseudonyms are used in the narratives presented in the results section. The codes were then analysed for patterns, pre-set themes, emerging themes and categories including food that is recommended during pregnancy, food that is restricted during pregnancy and the underlying reasons, opinions on the beliefs and who gave the advice. The SPSS program (version 23) was used to establish the frequencies of descriptive statistics.

\section{Ethical considerations}

The research study was commenced after being approved by the National Commission for Science, Technology and Innovation (NACOSTI), Kenya. At the county level, research clearance was issued by the Uasin Gishu County Commissioner of Health, the County Administration Commissioner and the County Commissioner of Education. Request to access individual health facilities was granted by officers in-charge of the facility prior to the actual data collection day. The study was explained to each respondent and those consenting to participate were then requested to sign a written consent form. The respondents could withdraw from participation or answering further questions whenever they wished. The respondents' identity was kept anonymous and their responses confidential.

\section{Results}

Findings reveal that food beliefs are widely known and practised by pregnant Kalenjin women. Respondents mentioned various reasons for certain foodstuffs being restricted or encouraged during pregnancy as indicated in Tables 2 and 3. Food beliefs were mainly acquired from their gogo (their grandmother or any age-equivalent woman in the neighbourhood). They also learned food beliefs from their mothers, mothers-in-law, and other older female relatives, friends and neighbours. Only those with certain health problems (low haemoglobin status, low weight increase, hypertensive, diabetic or HIV positive) learned from health practitioners. Below, we present the results on pregnancy food restrictions, followed by food recommendations.

\section{Food restrictions during pregnancy}

Several food avoidances were identified during the study and the underlying reasons for these practices are identified in Table 2 below. The foods to be avoided by pregnant women were organ meat (with exception of liver), mentioned by $96 \%$ of the respondents, meat (87\%) and eggs (68\%), oily food (25\%), avocados (Persea americana) (20\%), alcohol and cigarettes (19\%), sugary food (11\%), soil and soft stones (11\%) and moboriet (left over ugali from the previous night commonly eaten as breakfast with other accompaniments) (10\%). Other mentioned food restrictions were below 7\%. Each of these (when above 10\%) is explained below in order of frequency.

\section{Animal organs}

Almost all respondents (96\%) indicated that pregnant women are not allowed to eat animal organs, such as the tongue, the heart, the male reproductive organs and the udder (liver excluded). These organs are commonly obtained from a cow, goat, sheep or chicken. They are preserved for men and women are not allowed to eat them except barren women or those in menopause. All respondents reported that they have not eaten them since childhood. Some reasons given for this were as follows.

"I think you can become barren if you eat the reproductive organs." (150602_001-80)

"My father told me that my baby will talk much if I eat the tongue." (150514_005-88)

Furthermore, a number of respondents felt that such restrictions were put in place by male members of the Kalenjin ethnic group to protect animal organs from being consumed by women for their own selfish gain. A key informant reported that if a woman eats any of these organs, even in the absence of men, she will be considered disrespectful because she is showing dominance (proving to be the ruler of the homestead) which is very wrong. In addition, some respondents reported that if a woman eats animal tongue, she will talk more than men when women are supposed to listen while men talk, both at the homestead or in a public gathering. Therefore, these animal organs were either to be thrown away or given to a man in the neighbourhood if men (husband or senior sons) are not present. Another key informant reported that a Kalenjin man's life traditionally evolved in the forest (a dangerous zone with wild animals) either hunting, fighting, herding animals or in 
Table 2 Food restricted during pregnancy

\begin{tabular}{|c|c|c|}
\hline Food type & Reason & $\begin{array}{l}\text { Percentage } \\
(N=154)\end{array}$ \\
\hline Animal organs ${ }^{a}$ & Preserved delicacy for men and burren or menopouse women, tongue makes baby and women talk much & 96 \\
\hline Meat ${ }^{\mathrm{b}}$ & Makes the baby big and brings misfortune to mother or baby & 87 \\
\hline Eggs & Makes the baby big, causes high blood pressure and colic pain in the baby & 68 \\
\hline Oily food ${ }^{c}$ & Causes colic pain to the baby and makes the baby's saliva ooze & 25 \\
\hline Avocado & Makes the baby big & 20 \\
\hline Alcohol and cigarettes & Results in a retarded, underweight and stunted child & 19 \\
\hline Soil/soft stones ${ }^{d}$ & Causes colic pain to baby and finishes baby's blood & 11 \\
\hline Sugary food ${ }^{e}$ & Causes colic pain to baby, makes baby's saliva drool & 11 \\
\hline Moboriet $^{f}$ & Makes the baby big, makes mother defecate a lot during birth, makes foetus docile & 10 \\
\hline Fresh milk & Makes the baby grow big & 7 \\
\hline Cabbages and kale & Are not nutritious, give the mother heartburn and nausea, use a lot of chemicals to grow & 6 \\
\hline Salt & Makes the baby's skin crack and peel, increases blood flow/pressure of the mother & 5 \\
\hline Sheep's head & Makes the baby have a blocked nose hence breaths with snoring sound & 5 \\
\hline Cold water & Weakens the mother's back ache after birth and prolongs labour pain & 5 \\
\hline Plantain & Makes the baby big & 4 \\
\hline Sheep meat & Causes allergies such as rashes to the baby's skin & 3 \\
\hline Vegetables grown on a burned soil & Cause burn-like rashes to the baby's skin & 3 \\
\hline Beans & Give the mother heartburn and nausea & 3 \\
\hline Fermented milk & Gives the mother heartburn & 3 \\
\hline Fermented porridge & Gives the mother heartburn & 3 \\
\hline Rice and Irish potatoes & Supply less energy & 3 \\
\hline
\end{tabular}

${ }^{\mathrm{a} T o n g u e}$, heart, udder and reproductive organs (commonly obtained from either goat, sheep, cow or chicken)

${ }^{b}$ The common ones are obtained from sheep, goat, cow or chicken

'Using excess frying oil on food and food that require a lot of oil in preparation and cooking for example shallow and deep fried food

${ }^{\mathrm{d}}$ This is pica, the craving and purposeful consumption of substances not commonly identified as food, is often reported among pregnant women

'Sweet food such as honey, soft drinks, sweet bananas, sugarcane, chocolates, sweets, tea or porridge with sugar

${ }^{f}$ Cold ugali (a paste of cooked maize flour, millet flour or sorghum flour, sometimes mixed with cassava flour), usually leftovers from the previous night and is normally taken in the morning as breakfast with other accompaniments

search of stolen animals. Thus, eating animal heart made them develop a strong and bold heart to face the tough challenges associated with forest life.

\section{Meat}

Women were advised to be cautious about eating any type of meat during pregnancy as reported by $87 \%$ of the respondents. The main reason for restricting meat was based on reasons related to the condition of the animal during life or upon death. Many respondents thought that the condition could in several ways be transferred to the pregnant mother and/or her unborn child. First, an animal that ever encountered pregnancy-related complications, such as miscarriage, stillbirth or death due to placenta retention, should not to be eaten. When a pregnant woman eats such meat, it was believed the animal will transfer "bad blood" to the mother and she will encounter similar complications during pregnancy and childbirth:
"If a cow is pregnant and a calf dies in the uterus, a woman should not eat it. Also, if a cow was giving birth and the placenta refused to come out a woman should not dare eat it. If you eat it, you will be like that cow". (150504_001)

This belief is strongly observed by the Kalenjin community, especially the Marakwet and the Keiyo. All respondents who held this belief did not eat such meat during pregnancy. In addition, pregnant women are not allowed to eat meat of an animal which died without being slaughtered because of the possibility of passing on a dangerous disease to the unborn child or the mother.

Furthermore, women refrain from eating meat because it may have unknown negative associations, for example:

"If a cow is born lame, when slaughtered you cannot eat it, we believe you may give birth to a lame baby. Even a stolen animal is not allowed, you will give birth to a thief." (150621_001-53) 
Table 3 Food recommended during pregnancy

\begin{tabular}{|c|c|c|}
\hline Food type & Reason & $\begin{array}{l}\text { Percentage } \\
(N=154)\end{array}$ \\
\hline Traditional vegetables (Table 4) & $\begin{array}{l}\text { Increase blood of the mother, gives strength to the } \\
\text { mother and reduces heartburn }\end{array}$ & 89 \\
\hline Milk & Gives strength to the mother, builds body and adds blood to the mother & 63 \\
\hline Fruits $^{a}$ & Increase blood to the mother and protect the baby & 35 \\
\hline Traditional herbs & $\begin{array}{l}\text { Give strength to the mother, protect the baby, immunity booster to mother } \\
\text { and foetus, reduce heartburn, 'evil eyes' and misfortunes and gastro-intestinal } \\
\text { discomfort, increases uterine contractions during labour }\end{array}$ & 34 \\
\hline Ugali $^{\mathrm{b}}$ & Gives strength to the mother & 32 \\
\hline Porridge & Gives strength to the mother and increases the mother's blood & 32 \\
\hline Liver $^{c}$ & Increases blood of the mother & 24 \\
\hline Water & Gives strength to the mother & 15 \\
\hline Animal blood ${ }^{d}$ & Increases blood of the mother & 13 \\
\hline Beans & Gives strength to the mother and increases blood of the mother & 12 \\
\hline Fish & Builds body and increases blood of the mother & 11 \\
\hline Red soil and soft stones ${ }^{\mathrm{e}}$ & Increases blood to mother & 7 \\
\hline Meat ${ }^{f}$ & Adds blood to, and builds body of, the mother & 7 \\
\hline Cooked bananas & Gives strength to the mother & 5 \\
\hline
\end{tabular}

${ }^{a}$ Oranges (Citrus sinensis), tangerine (Citrus reticulate), tamarillo (Solanum betaceum), passion (Passiflora edulis), pineapples (Ananas comosus), pawpaw (Carica papaya), Tamarillo

${ }^{b}$ Locally known as Kimyet a paste of cooked maize flour, millet flour or sorghum flour, sometimes mixed with cassava flour

'Commonly obtained from either sheep, goat, cow or chicken

${ }^{\mathrm{d}}$ Obtained from either sheep, goat or cow

eAlso called pica, the craving and purposeful consumption of substances not commonly identified as food

${ }^{f}$ Commonly obtained from goat, sheep, cow, or chicken

Among the Kalenjin community, it is a taboo for pregnant women to eat the meat of an animal which died by strangling because it is believed that the spirits of this animal will follow the baby and kill it by coiling the umbilical cord around the baby's neck.

A number of respondents also noted that an animal that was struck by lightning could only be eaten by men because it would kill women:

"Meat of an animal killed by lightening is not even allowed to be brought into the house; it is

Table 4 Traditional vegetables

\begin{tabular}{llll}
\hline No. & Local name & English name & Botanical name \\
\hline 1 & Mborochet & Pig weed & Amaranthus dubuis \\
2 & chepkerta & Pig weed & Amaranthus gracecizane \\
3 & Sochojek & African nightshade & Solanum nigrum \\
4 & Sagek & Wild spiderflower & Cleome gynandra \\
5 & Nderemiat & Vine spinach & Basella alba \\
6 & Seveve & pumpkin leaves & Cucurbita moschata \\
7 & Mrenda & jute mallow & Corchorus olitorius \\
8 & Mito/miroo & Slenderleaf & Crotalaria ochroleuca \\
9 & Kundek & Cowpea leaves & Vigna unguiculata \\
\hline
\end{tabular}

slaughtered and eaten by men at the striking spot. The leftovers including bones should be burned beyond recognition. ...It can cause death to a pregnant woman if she eats it". (150610_003-77)

Therefore, if a pregnant woman wants to eat meat she needs to know the history of the animal:

"If you are pregnant and you are not sure of a certain meat, don't attempt to eat it, you ask first. But this is something everybody knows, even the owner of the meat will not let you eat it or buy it if he notices that you are pregnant. He will stop you." (150602_001)

In case a woman eats such "evil" meat by mistake she has to undergo certain cleansing rituals.

"If you accidentally eat an animal that was unable to deliver and died, they must do for you cleansing rituals. This will involve people from the husband side and the wife side. After the rituals, nothing will happen to you". (130709_006-129)

A key informant explained that some of the herbs consumed during pregnancy neutralise the effect of this "evil meat" if eaten unknowingly by the mother. 
In some cases respondents referred to specific kind of animals that should not be eaten. Some respondents reported that a pregnant woman should avoid beef, because cattle receive routine treatment, such as injections and immunisations that could be a health hazard to the foetus.

"They restrict meat from cattle too, but sheep, goats are allowed... personally I did not eat it. It is not allowed, because cattle are given a lot of drugs." (130709_002-126)

Eating mutton during pregnancy, as reported by $3 \%$ of the respondents, will cause health problems in the newborn baby:

"I did not eat mutton, even 'gogo' told me not to. You know if you eat mutton, when you give birth, the meat brings rashes on your baby's skin, like those of an allergy." (130707_005-106)

"Meat of sheep's head is not allowed to be eaten by a pregnant woman, the child will have nasal block. Have you ever heard a child snoring strongly even when awake? They say it's because you ate sheep's head during pregnancy." (150510_003-1)

Several respondents noted that meat should not be eaten "in excess" by a pregnant woman - at most once a week because it has proteins that make the baby grow big, causing problems during birth.

\section{Eggs}

Eggs are believed to be either "too strong" or "too heavy" or to have "too much protein" and are hence not good for a pregnant woman. This view was shared by $68 \%$ of the respondents. In this study, it was believed that strong foodstuffs such as eggs are believed to make the foetus grow excessively big and this will cause problems to the mother during birth. They further had different views about eating eggs as stated below:

"We are told if you eat eggs, they will bring problems on the day of birth, the baby will defeat you, and you will undergo an operation [caesarean section]." (150510_002-25)

"They say that if a woman is pregnant and eats eggs, there are high chances of developing high blood pressure." (130707_004-105)

"You know if you eat eggs, the baby will develop stomach pain, and she/he will be crying a lot after birth." (150510_003-1)
A pregnant woman should preferably avoid eggs completely during the entire period of pregnancy. If it is essential that a woman eats eggs (for example due to hospital recommendations or pregnancy "urges") she should only eat a few eggs or mix them with other food such as chapati (Flat round shallow fried substance made from wheat flour, salt, sugar and oil) or vegetables to neutralise the effect:

"I find it a wise idea not to eat eggs when pregnant. You should eat may be once, ... say after a month or two months if you have that strong urge, otherwise, you are supposed to control yourself”. (130707_004-105)

"I ate twice for the entire pregnancy period but I did not eat them plainly. I mixed them in dough for making 'chapati' and in 'sukuma wiki' [Brassica Carinata]." (150610_001-75)

Some respondents mentioned that the effect of eggs is more severe at certain stages of pregnancy although these stages differed:

"We are restricted eggs from six months onwards." (130707_008-107)

"A woman cannot eat eggs from the time of conception but after finishing 6-7 months it is allowed." (130709_006-129

\section{Oily food}

Some of the respondents (25\%) reported that "too much oil" is not recommended for a pregnant woman. It is considered "too much oil" when food is prepared using a lot of oil, especially deep frying. The reported foods of this kind include chapati, mandazi, ${ }^{1}$ kangumu, ${ }^{2}$ eggs, French fries and fatty meat. The main reason for avoiding fatty food is that it causes colic pain to the baby. It can also make the baby fat (making the birth difficult), and cause high blood pressure and malaria in the mother:

"The food that has a lot of oil for example eggs, 'kangumu,' 'mandazi', or fatty meat, you should not eat much. ... I don't know what it has that if you eat, the day of delivery it will bring problems, you will undergo an operation." (150510_002)

"You should use very little oil in frying food, not excess because a pregnant woman's blood already flows very fast. If you add oil on top, the heart will beat excessively." (130707_002-104) 


\section{Avocado (Persea Americana)}

Avocado is also restricted during pregnancy as reported by $20 \%$ of the respondents. Avocado is believed to have similar effects as eggs. It causes the baby to grow "fat", causing delivery problems. It should therefore be avoided completely or eaten once in a while (one in a week).

"Avocado can hurt you ... This is something I was told by my mum and I believed it. ... If you eat it, you are causing problems to yourself, you might tear during birth or you will not be able to push out the baby." (150617_002-9)

"They have said I should avoid it [avocado], though I used to it eat because I didn't know it was wrong until I was stopped. ... it is a good idea, because if you eat, the baby will grow ..., and if the baby grows big, definitely you will go to theatre." (150621_001-53)

"Avocado you only eat once in a week. I personally did not eat it completely. I find it an okay advice, because if you eat, the baby will be too heavy and you will not be able to deliver." (130709-002-126)

\section{Alcohol and cigarettes}

According to $19 \%$ of the respondents alcohol and cigarettes are restricted. They are believed to cause low birth weight and stunted children because they "suck the baby's blood". They also affect the baby's brain, causing retardation in children.

\section{Sugary food}

Other respondents (11\%) reported that "a lot of sugar" is not good when a woman is pregnant. Sugar in this case refers to sugar plus any foodstuffs known to be "sweet", including (in order of prevalence) sugarcane, honey, sweet/ripe bananas, sweets, chocolates, and sugared beverages and drinks such as tea, soda and processed juice. Women held a belief that the baby will salivate excessively if the mother had ingested sugary foods during pregnancy. Sugary foods are also believed to give the baby colic pain and may give mother and baby malaria:

"If you eat sugarcane, your child will have this thing... we call it 'meninek' I mean will be oozing a lot of saliva.”(150615_002-98)

"We call it 'surunda' (colic pain) this stomach that disturbs newborns. Ripe bananas are not good." (130708_001-118)

\section{Soil and soft stones}

During pregnancy, some women crave and purposefully consume non-food items such as soil, chalk, laundry starch, ice, or cigarettes which they claim has a good taste or smell. This habit is commonly known as pica (a Latin word for magpie, the bird notorious for eating almost anything) and the patterns of ingestion are referred to as "Phagia" [38]. In this study, $11 \%$ of the respondents reported pica. Often reference was made to the practice of eating clay soil, commonly obtained from termite mounds or dry mud walls of houses (geophagia) and soft stones (lithophagia). These stones are mostly light-yellow in colour and are sold in open-air markets, supermarkets or can be picked along the way. Ingestion of soil and soft stones is a common behaviour among women in Kenya, especially during pregnancy [38-41]. However, in this study, many respondents reported that soil and stones should be avoided during pregnancy because they would give newborn babies colic, cause anaemia in the mother, and the mother will give birth to a baby who will be eating soil.

\section{"I did not eat soil so my baby had this normal stomach problem, but if you add the soil on top the problem becomes excess." (150617_002-9) \\ "I was having four pints of blood (Hb4) when I was pregnant of my other daughter... And that is why I was telling you that soil finishes blood because I used to eat a lot of it even before I conceived that pregnancy.” (130707_005-106)}

A key informant reported that if burnt soil (obtained from wall of burned mud house and clay cooking stones) is consumed by a pregnant woman, the child will develop burn-like skin rashes which cannot be treated at the hospital and which can only be cured using traditional herbs mixed with a powder of burnt soil.

\section{Moboriet}

Another pregnancy food restriction mentioned by $10 \%$ of the respondents was moboriet. Moboriet is ugali left over from the evening meal. Among the Kalenjin, moboriet is commonly eaten with hot tea or fermented milk as breakfast, especially by women in most rural homesteads. Respondents consider that consumption of moboriet by a pregnant woman will make the foetus oversleep, docile in the womb, fat and difficult to deliver. It was also mentioned that moboriet will cause a pregnant woman to defecate during birth, troubling the midwife:

"You should not eat moboriet when you are pregnant especially in the morning. A woman poops all the time during birth before the baby comes out. They [the midwives] will be wiping it off every time that is why they do not let us eat it." (150609_002-89) 


\section{Other pregnancy food restrictions among the Kalenjin}

Respondents reported many other food restrictions, although these were less frequently mentioned $(<7 \%$ of the respondents). For example, fresh milk, especially when hot, was believed to make the baby grow big and difficult to deliver. Instead, mursik (fermented milk) was recommended. However, others reported that mursik gives pregnant woman heartburn hence fresh milk is preferred. Beans, fermented porridge and kale (Brassica Carinata) are also associated with heartburn during pregnancy. Three women believed that taking salt or soda ash during pregnancy will cause the baby to have rough, dry and cracking skin which will eventually start to peel off like that of a snake. Other foodstuffs such as wild cabbages (Brassica oleracea) and kale (Brassica Carinata) are believed to be nutritionally less valuable foods while rice (Oryza sativa), Irish potatoes (Solanum tuberosum) and plantain (Musa $\times$ paradisiaca) are believed to be 'light' food, supplying less energy, and should not be frequently consumed by pregnant women.

Eating vegetables grown on burned ashes or burned soil is believed to cause dangerous burn-like rashes all over the skin baby's skin, similar to those mentioned earlier that are caused by eating burned soil. Drinking cold water during pregnancy and during labour is restricted because it is believed to weaken the mother's back and prolong the labour pains.

\section{Food types recommended during pregnancy}

The types of food items recommended for consumption by pregnant women, and why they are considered important, are presented in Table 3 below.

Four dominant nutritional beliefs attributed to the recommended foodstuffs emerged. These types of food were believed to either "increase blood", "increase mother's strength", "build the body of mother" or protect the mother and child from disease. The commonly cited food recommended for pregnancy include traditional vegetables (89\%), milk (63\%), fruits (35\%), traditional herbs (34\%), ugali (32\%), porridge (32\%), liver $(24 \%)$, meat $(18 \%)$, water $(15 \%)$, animal blood (13\%), and beans (12\%). Some of these are discussed in more details below.

Traditional vegetables The consumption of traditional or indigenous Kenyan green vegetables during pregnancy is one common cultural food belief and practice that was reported by almost all respondents (89\%). The consumption of traditional vegetables is not only highly recommended by the gogos but it is also advised by health workers as a nutritional therapy for pregnant women with lower $\mathrm{Hb}$ levels. Traditional vegetables identified by respondents include pigweed (Amaranthus dubuis and Amaranthus gracecizane), African black nightshade (Solanum nigrum), wild spider flower (Cleome gynandra), vine spinach (Basella alba), pumpkin leaves (Cucurbita moschata), slender leaf (Crotalaria ochroleuca) and cowpea leaves (Vigna unguiculata). Spinach is the only exotic green vegetable recommended for increasing the volume of blood. All the recommended vegetables are deep green and leafy. They are grown in gardens and farms, although some also grow as weeds along footpaths and in uncultivated fields. Mostly they do not require maintenance use of pesticides and artificial fertilisers. As a result, these vegetables are widely available within Uasin Gishu County. The vegetables are prepared as a sauce with cream obtained from cow's milk, salt, and tomatoes. No oil is added but a few mentioned enriching it by adding animal blood when cooking.

These vegetables were generally considered to "increase the volume of blood" in a woman's body and to "build body" which gives women strength during labour. Unlike other exotic vegetables which grow in the study area, such as wild cabbage (Brassica oleracea) and kale (Brassica Carinata), traditional vegetables are not believed to cause heartburn and they are considered to digest easily, relieving constipation. For these reasons, traditional vegetables are preferred by all members of the community. Various respondents reported the importance of eating traditional vegetables:

"This nderemiat [Basella alba] and miroo [Crotalaria ochroleuca) are very helpful, when you eat them you do not feel heartburn." (150602_001)

"When you are pregnant and your blood is low, you must eat these vegetables so that your blood can increase." (150617_006-13)

Milk and blood Milk, according to $63 \%$ of the respondents, is believed to "increase the volume of blood", "give strength" and "build the body" of the mother. To boost its nutritional value, milk is mixed with raw blood extracted from a healthy bull or collected from the slaughterhouse. Milk mixed with blood is believed to raise blood volume very rapidly. As a result, it is highly recommended for women who were informed at the clinic that their $\mathrm{Hb}$ is low:

"When you are pregnant and you are told your blood is less and should be increased, you need to go to the butchery, collect blood of the cow, sheep or goat depending on what animal they slaughtered, ferment it with fresh milk, stock and you be drinking it daily. It helps your blood volume to increase fast." (130707_003-104)

Animal blood can also be consumed without milk. It is normally cooked until it hardens and served as a meal. The consumption of blood is a prominent Kalenjin 
custom of the past as explained by a key informant. However, the consumption of blood is being discouraged by the public health officers on the grounds that animals receive injections in various treatment regimes that might not be good for human health.

Fruits Some 35\% of respondents reported that eating fruit, with the exception of avocado and ripe bananas, was recommended because fruit is believed to increase the mother's blood volume. The commonly reported fruit known to increase blood were the tamarillo (Solanum betaceum) and oranges (Citrus sinensis). Other fruits mentioned in the study include: tangerine (Citrus reticulate), passion fruit (Passiflora edulis), pineapple (Ananas comosus) and pawpaw (Carica papaya).

Fruits are also believed to improve mother's appetite, help in digestion, and improve the skin of the baby after birth.

Ugali Thirty two percent of the respondents reported that Ugali is recommended for pregnancy. Ugali is the local staple food among Kenyan communities including the Kalenjin. It is most often made from maize flour, but also from millet or sorghum flour, or a mix of cereals, and is cooked with water until a dough-like substance is attained. Maize is affordable and widely available in Uasin Gishu County and is grown for subsistence as well as commercially. Ugali is consumed with vegetables, fermented milk, or meat stew. Ugali made from a mixture of sorghum and finger millet flour is highly recommended during pregnancy. This type of ugali is believed to be nutritious and "stronger" than the ugali made from maize flour. The majority of the respondents believe that ugali gives strength to the mother:

"Ugali is good. It gives you energy the day of pushing the baby out." (150602_001)

Traditional herbs Consumption of traditional herbal medicine is also highly recommended for pregnant women as reported by $34 \%$ of the respondents. The traditional herbal medicine comprises 10 different mixed plants. A key informant (herbalist who supplies herbs to pregnant women) explained that the plant extracts (roots, leaves, twigs or bark) are either boiled until they reduce to a small concentrate $(500 \mathrm{ml})$ locally known as sagetiek (in Nandi language) or are burned to form an ash-like powder (known as bosarok). It is recommended that a woman consumes a quarter of a glass of sagetiek three times a day for two weeks, break for a month and then resumes with a similar dose. It is also consumed two days before the due date and when the mother is overdue. Sagetiek is either taken alone, or in some cases combined with honey or soup if extracted from bitter plants. The soup is made from the head and hooves of an animal, preferably a goat or cow. On the other hand, bosarok is licked daily for a prescribed period because it is believed to protect pregnant women from an evil eye and witchcraft that might affect the unborn child. Respondents consider that bosarok is very useful, especially when the pregnant women expect to meet a lot of people who might put a curse on the baby. In addition, bosarok is also considered to relieve heartburn and reduce nausea.

Women can purchase herbal remedies from a known herbalist in the village. The herbs are believed to be useful and it is generally considered that they should be consumed by a pregnant woman whether sick or not. Sagetiek, as explained by key informants, is believed to protect pregnant woman from getting sick and from transferring sickness to the foetus. It is also believed to make the woman strong and increase blood volume, facilitating easy birth by accelerating labour and cervical dilation. It is also believed to build the body and health of the foetus, change the sex of the foetus from girl to boy, neutralise the effects associated with eating "evil meat", and regulate the size of the baby. The herbs are also believed to clean the foetus's skin and stomach, give the baby smooth, rash-free skin, reduce a baby's colic pain and decrease its vulnerability to communicable diseases when born. Thus, sagetiek is widely recommended for pregnant women.

Porridge Recommendation of porridge during pregnancy was reported by $32 \%$ of the respondents. Porridge, when prepared from the flour of finger millet mixed with sorghum, is believed to increase the volume of blood. In addition to boosting blood volume, porridge is believed to give pregnant woman strength hence it is particularly recommended for consumption during breakfast and in-between the meals.

Liver Twenty four percent of the respondents reported that liver is highly recommended for pregnancy because it increases the volume of blood. Whenever an animal is slaughtered in the village, liver is specifically reserved for any pregnant woman or children within that homestead. Liver is also advised by health workers to pregnant women with lower $\mathrm{Hb}$ levels.

Other food recommendations Other recommended food stuffs which were reported by less than $20 \%$ of the respondents, including meat, soup of red beans, fish, red soil and red stones, are believed to increase pregnant woman's blood volume. Cooked bananas and water during pregnancy are believed to increase the strength of the mother. In addition, when an animal is slaughtered (mostly goat, sheep, cow or chicken), its liver is preserved for any pregnant woman in the homestead. It 
is believed to increase the volume of blood hence recommended for pregnant women.

\section{Discussion}

The results demonstrate that food beliefs and practices are still commonly subscribed to and practised by a large majority of the contemporary Kalenjin pregnant women of Uasin Gishu County. These findings are comparable with those of Ekwochi et al. [23] and Zepro [25] who found that more than half of the women in south-east Nigeria and Ethiopia, respectively, had traditional food beliefs.

Protection of human health emerged as the dominant reason for practising food beliefs in this study. Protection of health conditions were also stated in the literature as reasons for the prevalence of food taboos in Ethiopia and Gambia [24, 25]. This is unlike other regions of Zambia where fear of foetal malformation and abnormality was established to be the major reason for pregnancy food beliefs [42]. Varied other reasons for subscribing to food beliefs during pregnancy emerged from the study as described below. This supports literature that indicates there is no single reason for the belief and adherence to food taboos [43].

\section{Health and illness as determinants of food selection and restriction}

The Kalenjin women adhere to food beliefs as a way of avoiding any calamity that might interfere with pregnancy and child birth. Child bearing among the Kalenjin is very important because it is the dominant way a woman acquires bride price, gains security, acceptance and identity in the family and the community [44]. Children constitute the most important visible sign of success and achievement in the society to both husband and wife [44]. Pregnancy food precautions as a concern for a healthy pregnancy and birth outcome was also established in Nigeria, Ethiopia and the Gambia [23-25]. Four principle lines of reasoning emerged from the responses that are believed to facilitate easy labour and birth, as indicated below:

First, the foetus should be kept small. It is considered that large foetuses are difficult to deliver, resulting in episiotomy, prolonged and obstructed labour and possibly caesarean section (CS), increase chances of death of the mother or child. Eggs, oily food, meat, fresh milk, Moboriet and cooked potatoes during pregnancy are believed to make the foetus grow excessively big, hence these foods are restricted. Prescription of herbs was also established as a remedy for regulating the size of the baby and to accelerate contractions during labour.

This study was carried out in a rural area where the largest accessible health institution is a health centre which only conducts normal deliveries, primary healthcare and basic first aid for obstetric complications. It is headed by a Clinical Officer who is not qualified to conduct surgery in case of an emergency [45]. It has also been established that the referral system in case of an emergency is very poor, exacerbated by poor rural road access $[45,46]$. Hence, respondents' fear of a complicated delivery is justified. Restricting the foetus from growing large as a way of facilitating easy birth was also established in Ghana, Ethiopia and South-East Nigeria [21-23, 25]. Consumption of cow's blood, sour milk and much water, as well as vomiting after a heavy meal, is also practised by the Maasai women in Kenya, also aiming to keep the baby small at birth to facilitate delivery [29].

According to the respondents, the occurrence of easy labour and birth is also determined by the strength of the woman. They consider that a weak woman cannot push out the baby easily and that she can even faint or die in the process. Such a woman can only be helped by $\mathrm{CS}$ which is, as mentioned above, believed to be a risky endeavour. For a woman to have enough energy reserves during birth, she is expected to consume food believed to give strength during her pregnancy period. Such food includes ugali and porridge made from finger millet mixed with sorghum, and traditional vegetables, milk, traditional herbs and meat. Similarly, Towns [19] also established how Beninese and Ghanian women consumed medicinal plants to strengthen women during pregnancy and that delivery would be facilitated through consuming these plants. On the other hand, energygiving starch-rich items were regarded as good for body among rural Nigerian mothers [47].

Another factor that is believed to facilitate easy labour and birth is to have sufficient blood. Fewer blood reserves make a woman weak. A woman with less blood is also believed to bleed excessively during labour, birth or after birth, which may necessitate a blood transfusion or cause death if she cannot access a health facility in time and get a willing blood donor. According to many respondents, the prominent way of ensuring enough blood is consuming plenty of traditional vegetables, liver, animal blood, fruits, milk, beans, red soil/stones and fish during the pregnancy period. On the other hand, a woman should avoid eating soil and soft stones (pica) because they are also believed to "suck" her blood (causing anaemia). Ingestion of pica involving soil and soft stones is a common behaviour among women in Kenya especially when pregnant [38-41], possibly representing a natural response to a nutritional depletion, such as iron deficiency $[39,48]$. Although consuming clay soils has been found in the literature to be medicinal [49], it can lead to reductions in birth weight, haemoglobin, haematocrit, and red blood cell levels, thus causing maternal anaemia [50]. Iron and folic-acid deficiency anaemia during pregnancy is very common in Kenya 
[51] and is associated with maternal death [28] hence the fear of iron deficiency among these women is justified. A belief in the importance of iron was also established among pregnant women in Ghana where, likewise, traditional green vegetables were believed to provide blood or prevent anaemia [20].

Evil spirits or supreme powers are also believed to interfere with good health outcomes by causing misfortune and complications during pregnancy, labour or birth. Death of an animal is sometimes believed to be caused by evil spirits and these evil spirits are transferable to humans. Therefore, if a woman eats the meat of a dead animal killed by evil spirits, these spirits can cause a similar death or misfortune to the mother or child. The commonly established powerful spirits are those that cause animal death through pregnancy-related complications such as miscarriage, stillbirth, retained placenta, foetal malpresentation or that cause an animal to hang itself, stricken by thunder, sickness, or animal deformity. Fieldhouse [52] identified food restrictions related to magical thinking in which some plants and animals (e.g. dogs, cats, pigs) were perceived to have spirits and were therefore not consumed.

Foods culturally recognised to cause "illness" were established to influence food choices in this study. Some foods were restricted because they are believed to cause sickness to mother and child: including neonatal death, skin rashes, colic pain, and nasal block or breathing difficulties in the infant and nausea feelings, vomiting, miscarriage, preterm birth and maternal death to the mother. Foods believed to cause these illnesses to the child include foods that are oily, sugary and salty. Eating soil, stones, mutton, sheep's head and vegetables grown on burned soil are also believed to cause these childhood illnesses. Notably, these illnesses which are caused by eating of restricted foods are not bio-medically treated. Instead, they are treated locally by use of various herbs. Studies have identified a comprehensive list of medicinal plants used by the Kalenjin herbalists to treat several ailments including skin rashes, colic pain, infertility and miscarriage [53, 54]. However, these studies tend to overlook the safety and efficacy of using these herbs and how herb consumption influences or prevents illness. A study by Towns [19] in Ghana established that most herbal plants have antibacterial, anti-inflammatory, antimicrobial and antimalarial activity. Use of herbal medicine to treat pregnancy-related health ailments is a common practice in rural and urban Kenya [55-57] as well as in Europe, Australia, Zambia, South Africa and Ghana [19, 58-60].

Some foods are not restricted by culture but are believed to cause discomfort, such as heartburns, nausea or vomiting, a condition the respondents referred to as "being rejected by the foetus". Commonly cited foods in this category include fermented poridge, fermented milk, cabbages, kale, beans and githeri (maize mixed with beans). Consumption of traditional vegetables and fresh milk is believed to relieve heartburns, nausea and vomiting, and is encouraged. Food cravings or rejection due to physiological changes that resulted in overconsumption or underconsumption of nutritious or non-nutritious food has previously been established by Aikins [20] among pregnant women in Ghana.

\section{Gender and age as determinants of food selection}

Some food stuffs were also judged to be more or less appropriate for certain classes of individuals in the society. Attributes of "male" versus "female" foods, their symbolism, and how they affect actual consumption of food were also established in the study. For instance, the Kalenjin men reserve some animal organs such as the tongue, heart, male reproductive organs and udder for themselves as delicacies; these foods are taboo for women and children. On the other hand, liver is reserved for any pregnant woman in the family. Subdivision of animal body parts/meat according to age and gender is a common cultural practice among the pastoralist communities in Kenya, including among the Kalenjin. Similarly, the Luhya community of Kenya restrict consumption of eggs in order to spare chickens because chicken meat is a delicacy reserved for men and guests [29]. Such a practice can result in a shortage of adequate supplies of essential nutrients, especially among vulnerable groups.

\section{Rituals as factors in food selection and avoidance}

In this study, herbal medicine, milk, animal blood and traditional beer were commonly used in conducting cleansing rituals when pregnant women accidentally consume restricted food stuffs. Herbal medicine as explained by a herbalist in this case is consumed by the pregnant women whereas traditional beer, animal blood and milk were moth sprayed at the grave yard as a reconciliatory negotiation between the pregnant woman and the ancestors. as a result, these herbal trees are domesticated in the gardens because they are getting diminished in the forests due to deforestation. The role of taboos as a protection of ritual plant species was also established by Quiroz in Benin and Gabon [16].

\section{Food beliefs observed to enhance decency and aesthetics} Some food restrictions are based on decency and aesthetics. Consumption of moboriet is believed by some to make a woman defecate during birth. At the same time, sugary food is believed to make the baby messy by encouraging saliva over production hence drooling. 


\section{Food beliefs to enhance group identity and cohesion}

The majority of the pregnancy food recommendations were indigenous to the Kalenjin diets generally and were termed as traditional foods (for example animal blood, milk mixed with blood, milk, green leafy vegetables, meat, fruits, beans, ugali and porridge made of finger millet and sorghum flour). The majority of the indigenous foods discussed cut across the sub-groups of the Kalenjin community. This signifies cultural identity, continuity, cohesion and a feeling of belonging and uniqueness in food consumption patterns in these Kalenjin sub-groups. It also probably indicates that pregnancy diet patterns have not changed much over time.

One of the limitations of this study is that the implications of the food beliefs during pregnancy on the nutritional status of Kalenjin women were not examined because it was not a research objective and because the study was subject to time and resource constraints. Future studies should use a combination of analysis of dietary intake such as food frequency questionnaire, food diary and 24-h dietary recall to determine the actual nutrient intake and nutritional status of the women.

\section{Conclusions}

The results of this study demonstrate that food beliefs and practices are still commonly subscribed to and practised by a large majority of the contemporary rural Kalenjin pregnant women. Some food beliefs such as eating traditional vegetables and milk, as well as restricting the consumption of organ meat (with exemption of liver), meat and eggs, are subscribed to by more than $60 \%$ of the respondents. Consumption of fruits, traditional herbs, ugali, porridge and liver, and restriction of avocadoes and oily food was reported by more than $20 \%$ of the respondents. The reasons cited for adherence to these dietary precautions were largely based on protection of human health, mainly in realising a successful pregnancy and delivery. Sufficient maternal blood, energy and restricting foetal size and evil contamination were believed to result in a successful pregnancy outcome. Protection of foetal ill health, such colic, skin rashes and malformations was also established, though much less frequent than the health of the pregnant woman. Other reasons such as monopoly of a scarce resource (organ meat), decency and aesthetics also emerged. Based upon these conclusions, we recommend the following:

- Considering the high prevalence of food beliefs, it is advisable that when nutritious foods are restricted, nutritional interventions should rather search for alternative sources of nutrition which are available and considered to be appropriate for pregnancy.
- In this study, we also found ambiguity in the food beliefs. Some food such as meat, beans, cooked bananas, soil, and milk were reported by some respondents as restricted, while these were mentioned by others as being recommended. Intervention programs should thus design nutrition training tools tailored to these intra cultural variations in food beliefs.

- Some of the beliefs, such as consumption of traditional vegetables, milk, beans, liver, fruits, porridge and ugali as well as the restriction of eating soil and soft stones, meat of a dead animal, excess salt, excess sugar, excess oil, alcohol and cigarettes, are supported by science and are indeed beneficial for health, hence need to be encouraged. However, it should be clarified how much should be consumed. On the other hand, restriction of nutritious food such as eggs, meat, avocadoes, animal organs, vegetables planted on ashes, as well as recommendation of red soil, need to be sparingly discouraged.

- Traditional herbs are widely consumed during pregnancy not only in Uasin Gishu but also in other parts of Africa. There is the need to study the chemical constituents of these herbs to learn how safe and relevant they are for human consumption, especially during pregnancy and foetal development.

- The major reason for food beliefs and adherence to them is to protect health of the mother and child, and ensuring a successful pregnancy outcome.

Intervention programmes that provide nutritional advice need to address these health concerns and the assumptions that underlie successful pregnancy and delivery, given the deep-rooted nature of the beliefs.

\section{Endnotes}

${ }^{1}$ Also known as Swahili bun, deep fried bread, similar to doughnuts, made from wheat flour mixed with salt, sugar and oil to taste.

${ }^{2} \mathrm{~A}$ type of mandazi but very compact and hard with no airspaces inside, made from wheat flour mixed with salt, sugar and oil to test and is deep fried

\section{Abbreviations \\ ANC: Antenatal clients; CS: Caesarean section; FAO: Food and agriculture organization; HB: Haemoglobin; HIV: Human immunodeficiency virus; IFAD: International fund for agricultural development; IUGR: Intra uterine growth restrictions; KNBS: Kenya national bureau of statistics; MCH: Maternal and child healthcare; NACOSTI: National commission for science, technology and innovation; PNC: Post-natal clients; SEKU: South Eastern Kenya university; TBAs: Traditional birth attendants; UNICEF: United nations international children's emergency fund; VU: Vrije Universiteit Amsterdam; WFP: World food program}

\section{Acknowledgements}

The authors would like to thank the people of Uasin Gishu County, especially the county health director, the in-charge of health facilities, key informants and the respondents, who were always willing to collaborate with us during the fieldwork. We also take the opportunity to thank our colleagues Margriet 
Bijholt, Dr. Willice Abuya, Vibian Angwenyi, and Dr. Mary Mwagombe whose contributions enriched the content of this work.

\section{Publisher's Note}

Springer Nature remains neutral with regard to jurisdictional claims in published maps and institutional affiliations.

\section{Funding}

The authors acknowledge the financial support by "A Sustainable Approach to Livelihood Improvement" (ASALI) Project. This is a joint collaboration Project of Moi University Kenya, South Eastern Kenya University (SEKU) and Vrije Universiteit Amsterdam (VU) that is being implemented in Kenya. This financial support proved fundamental to the design of the study, the collection and analysis of the data, and the writing of this manuscript.

\section{Availability of data and materials}

The data base will not be shared because it is not in any agreement with the Uasin Gishu Community.

\section{Authors' contributions}

$\mathrm{RR}$, a Doctorate Candidate, is the main author. She contributed to the conception, study design, planning, data collection, analysis and interpretation and prepared a first draft of the paper. JB is the supervisor and AN the mentor of RR's PhD program. They both contributed to the study design and interpretation of results. All the authors critically revised the paper and approved the final manuscript for submission.

\section{Authors' information}

Roselyter Monchari Riang'a is an Assistant Lecturer in Sociology department at Moi University, Kenya, and a PhD candidate of Maternal Nutrition and Health at Athena Institute of the VU University, Amsterdam. Prof. Dr. Jacqueline Broerse is a professor of Innovation and Communication in the Health and Life Sciences at the VU. She is also the Director of the Athena Institute, VU University, Amsterdam. Prof. Anne Nangulu is the Deputy Commission Secretary (Quality Audit and Standards) at the Commission for University Education (CUE) in Kenya and a professor of History, School of Arts and Social Studies at Moi University, Kenya.

\section{Competing interests}

The authors declare that they have no competing interests.

\section{Consent for publication}

The people interviewed were informed about the study's objectives and the eventual publication of the information gathered, and they were assured that the informants' identities would remain undisclosed.

\section{Ethics approval and consent to participate}

The authors were granted permission by the National Commission for Science, Technology and Innovation (NACOSTI) in Kenya, local authorities and the people interviewed to carry out the research for study. This is as per the ethical consideration of research and the Kenyan Government research policy

\section{Author details}

'Moi University, School of Arts and Social Sciences, P.O. Box 3900-30100, Eldoret, Kenya. ${ }^{2}$ Athena Institute, Faculty of Earth and Life Sciences, VU University Amsterdam, De Boelelaan 1085, 1081 HV Amsterdam, The Netherlands. ${ }^{3}$ Commission for University Education, Red Hill Road, off Limuru Road, GigiriP.O. Box 54999 - 00200, Nairobi, Kenya.

Received: 24 December 2016 Accepted: 8 May 2017 Published online: 25 May 2017

\section{References}

1. FAO, IFAD, WFP. The State of Food Insecurity in the World: Meeting the 2015 international hunger targets: taking stock of uneven progress. $\mathrm{FAO}$, IFAD WFP. 2015. Available from: http://www.fao.org/3/a4ef2d16-70a7-460aa9ac-2a65a533269a/i4646e.pdf

2. Barker DJP. Adult consequences of fetal growth restriction. Clin Obstet Gynecol. 2006:49:270-83.
3. Black RE, Victora CG, Walker SP, Bhutta ZA, Christian P, De Onis M, et al. Maternal and child undernutrition and overweight in low-income and middle-income countries. Lancet. 2013;382:427-51.

4. Black RE, Allen LH, Bhutta ZA, Caulfield LE, de Onis M, Ezzati M, et al. Maternal and child undernutrition: global and regional exposures and health consequences. Lancet. 2008;371:243-60.

5. Unicef. Committing to child survival: a promise renewed. eSocialSciences. 2015

6. Kenya National Bureau of Statistics (KNBS); ORC Macro. Kenya Demographic and Health Survey 2008-09. Nairobi: Government Printer; 2010.

7. Kenya National Bureau of Statistics, ICF Macro. Kenya Demographic and Health Survey 2014. Nairobi: Government Printer; 2014.

8. Gewa CA, Oguttu M, Yandell NS. Maternal nutrition in rural Kenya: health and socio-demographic determinants and its association with child nutrition. Matern Child Nutr. 2012;8:275-86. Available from: file:///:/ ARTICLES/Nutrition researches in kenya/Maternal nutrition in rural Kenya health and socio\%25E2\%2580\%2590demographic determinants and its association with child nutrition.htm.

9. Kabubo-Mariara J, Ndenge GK, Mwabu DK. Determinants of children's nutritional status in Kenya: evidence from demographic and health surveys. J Afr Econ. 2009;18:363-87.

10. Wiig Dammann K, Smith C. Factors Affecting Low-income Women's Food Choices and the Perceived Impact of Dietary Intake and Socioeconomic Status on Their Health and Weight. J. Nutr. Educ. Behav. Elsevier Inc. 2009; 41:242-53. Available from: http://dx.doi.org/10.1016/j.jneb.2008.07.003

11. Kaluski DN, Ophir E, Amede T. Food security and nutrition - the Ethiopian case for action. Public Health Nutr. 2002:5:373-81.

12. The Presidency of the Republic of Kenya. DRAFT: National Policy for the Sustainable Development of Northern Kenya and other Arid Lands "Unlocking Our Full Potential for Realization of the Kenya Vision 2030." 2015:52. Available from: http://www.devolutionplanning.go.ke/

13. Government of Uasin Gishu County. Uasin Gishu County Intergrated Development Plan 2013-2018. Nairobi: Government Printer; 2013.

14. UNICEF. The state of the world's children 2009: maternal and newborn health. Vol. 9. unicef, 2008.

15. Saj TL. Traditional taboos in biological conservation: the case of colobus vellerosus at the boabeng-fiema monkey sanctuary, Central Ghana. Soc Sci Inf. 2006:45:285-310.

16. Quiroz D, van Andel T. Evidence of a link between taboos and sacrifices and resource scarcity of ritual plants. J Ethnobiol Ethnomed. 2015;11:5. Available from: http://www.ethnobiomed.com/content/11/1/5.

17. Bénabou R, Tirole J. Identity, morals, and taboos: beliefs as assets. Q J Econ. 2011;126:805-55.

18. Golden CD, Comaroff J. The human health and conservation relevance of food taboos in northeastern Madagascar. Ecol Soc. 2015;42:20.

19. Towns AM, Van Andel T. Wild plants, pregnancy, and the food-medicine continuum in the southern regions of Ghana and Benin. J. Ethnopharmacol. Elsevier. 2016:179:375-82.

20. Aikins A. Food beliefs and practices during pregnancy in Ghana: implications for maternal health interventions. Health Care Women Int 2014:9332.954-72.

21. Demissie T, Muroki N, Kogi-makau W. Food taboos among pregnant women in Hadiya zone. Ethiop J Heal Dev. 1998;12:2-7. Available from: http://www.ethiopianreview.com/1995/Tsegaye_Demissie_Nelson_Muroki_ Wamboi_Kogi_Makau_1995.pdf.

22. Arzoaquoi SK, Essuman EE, Gbagbo FY, Tenkorang EY, Soyiri I, Laar AK. Motivations for food prohibitions during pregnancy and their enforcement mechanisms in a rural Ghanaian district. J Ethnobiol Ethnomed. 2015;11. Available from: http://www.ethnobiomed.com/content/11/1/59.

23. Ekwochi U, Osuorah CDI, Ndu IK, Ifediora C, Asinobi IN, Eke CB. Food taboos and myths in South Eastern Nigeria: the belief and practice of mothers in the region. J Ethnobiol Ethnomed. 2016;12. Available from: http://www. ethnobiomed.com/content/12/1/7.

24. Pérez GM, García AP. Nutritional taboos among the fullas in upper river region, the Gambia. J Anthropol. 2013;2013:1-9.

25. Zepro NB. Food taboos and misconceptions among pregnant women of Shashemene District, Ethiopia, 2012. Scinence J Public Heal. 2015:3:410-6

26. Ogbeide O. Nutritional hazards of food taboos and preferences in Mid-West Nigeria. Am J Clin Nutr. 1974;27:213-6.

27. Onyesom I, Onyesom C, Ofili MI, Anyanwu BE, Uzuegbu U. Effect of cultural beliefs and forbidden foods on the ABCD parameters of nutrition among some children in Nigeria. Middle-East J Sci Res. 2008;3:53-6. 
28. Ties Boerma J, Mati JKG. Identifying maternal mortality through networking: results from coastal Kenya. Stud Fam Plann. 1989;20:245-53. Available from: http://www.scopus.com/inward/record.url?eid=2-s2.00024728064\&partnerID=tZOtx3y1.

29. Oniang'o RK. Komokoti a. Food habits in Kenya: the effects of change and attendant methodological problems. Appetite. 1999;32:93-6.

30. Messer E. Methods for determinants of food intake. In: Pelto GH, Pelto PJ, EM, editors. Res. Methods Nutr. Anthropol. First. Hong Kong: United Nations University Press; 1989. p. 217.

31. Blumer H. Symbolic interactionism; perspective and method. 11th ed. Calfornia: University of California Press; 2009.

32. Department of Health Services. Uasin Gishu County Health Strategic and Investment Plan 2013 - 2018, Nairobi: Government Printer; 2013.

33. Kothari CR. Research methodology: methods and techniques. New Delhi: New Age International (P) Limited; 2004.

34. Gray DE. Doing research in the real world. London: Sage Publications; 2004.

35. Verschuren $P$, Hans D. Designing a research project. secondth ed. The Hague: Eleven International Publishing; 2010.

36. Grinnel RM, Unrau YA. Social work research and evaluation: foundations of evidence based-evaluations. 8th ed. New York: Open University Press; 2007.

37. KNBS. The 2009 Kenya population and housing census - population distribution by Age, Sex and administrative units. 2010. Available from: http:// www.knbs.or.ke/index.php?option=com_phocadownload\&view= category\&download=584:volume-1c-population-distribution-by-age-sex-andadministrative-units\&id=109:population-and-housing-census-2009\&ltemid=599.

38. Ngozi PO. Pica practices of pregnant women in Nairobi, Kenya. East Afr Med J. 2008;85:72-9.

39. Miller JD, Collins S, Krumdieck NR, Wekesa P, Onono M, Young SL. Pica is associated with lower hemoglobin concentration in a cohort of pregnant Kenyan women of mixed HIV status. FASEB J. 2016;30:1149.26. Available from: http://www.fasebj.org/content/30/1_Supplement/1149.26.abstract.

40. Gathura G, Njagi D. Women eating tonnes of stones. Dly. Nation. Nairobi. 2008. Available from: http://www.nation.co.ke/news/1056-453348-kp49biz/ index.html

41. Chung EO, Fiorella K, Omollo DO, Mattah B, Brashares J, Fernald LCH. Characteristics of pica behaviors among women in Western Kenya. FASEB J. 2016;30:1149.3. Available from: http://www.fasebj.org/content/30/1_ Supplement/1149.3.abstract.

42. Maimbolwa MC, Yamba B, Diwan V, Ransjö-Arvidson AB. Cultural childbirth practices and beliefs in Zambia. J Adv Nurs. 2003:43:263-74.

43. Meyer-Rochow VB. Food taboos: their origins and purposes. J Ethnobiol Ethnomed. 2009;5:18.

44. Chebet S, Ton D. Climbing the cliff: a history of the Keiyo. Nairobi: Moi University Press; 2000.

45. Mwaliko EW. Maternal mortality in Uasin Gishu District, Kenya: An exploration of coverage and use of maternal health care services. Masters Thesis, KIT (Royal Tropical Institute)Vrije Universiteit Amsterdam; 2009.

46. Essendi H, Johnson FA, Madise N, Matthews Z, Falkingham J, Bahaj AS, et al. Infrastructural challenges to better health in maternity facilities in rural Kenya: community and healthworker perceptions. Reprod Health. 2015;12:103. Available from: http://www.pubmedcentral.nih.gov/articlerender.fcgi?artid= 4640392\&tool=pmcentrez\&rendertype=abstract.

47. Ebomoyi E. Nutritional beliefs among rural Nigerian mothers. Ecol Food Nutr. 1988;22:43-52.

48. Roy A, Fuentes-Afflick E, Fernald L, Young S. Pica is Prevalent and Strongly Associated with Iron Deficiency, but not Anemia, among Mexican-born Pregnant Women Living in the United States. FASEB J. 2015;29. Available from: http://www.fasebj.org/content/29/1_Supplement/590.4.abstract

49. Abrahams PW. Geophagy (soil consumption) and iron supplementation in Uganda. Trop Med Int Heal. 1997;2:617-23.

50. Patterson EC, Staszak DJ. Effects of geophagia (kaolin ingestion) on the maternal blood and embryonic development in the pregnant rat. J Nutr. 1977;107:2020-5. Available from: http://www.ncbi.nlm.nih.gov/pubmed/ 561832

51. Republic of Kenya. National Food and Nutrition Security Policy. Nairobi: Government Printer; 2011.

52. Fieldhouse P. Food and nutrition: customs and culture. Second. Canada: Springer-Science + Business Media Dordrecht; 1995.

53. Amuka O, Okemo PO, Machocho AK, Mbugua PK. Ethnobotanical survey of selected medicinal plants used by Ogiek communities in Kenya against microbial infections. Ethnobot Res Appl. 2014;12:627-41. Available from: https://www.scopus.com/inward/record.uri?eid=2-s2.084937542356\%7B\&\%7DpartnerID=40\%7B\&\%7Dmd5= 976c706e73da680a80df33db9b2d1302.

54. Kipkore W, Wanjohi B, Rono H, Kigen G. A study of the medicinal plants used by the Marakwet Community in Kenya. J. Ethnobiol. Ethnomed. Journal of Ethnobiology and Ethnomedicine. 2014;10:24. Available from: http://www.ncbi.nlm.nih.gov/pubmed/24555424\%5Cnhttp://www. pubmedcentral.nih.gov/articlerender.fcgi?artid=PMC3974104

55. Hillary NC. Utilization of herbal medicine during pregnancy, labour and post-partum period among women at Embu provincial general hospital. Nairobi University, college of humanities and social science, Sociology: unpublished thesis; 2013

56. Kaingu CK, Oduma JA, Kanui TI. Practices of traditional birth attendants in Machakos District, kenya. J Ethnopharmacol. 2011;137:495-502. Available from: http://ac.els-cdn.com/S0378874111004090/1-s2.0-S0378874111004090main.pdf?_tid=41a99bf2-f8a7-11e4-b07d-00000aacb361\&acdnat= 1431435977_24d6321d00c99d0e264a9f6cda97caaa.

57. Mothupi MC. Use of herbal medicine during pregnancy among women with access to public healthcare in Nairobi, Kenya: A cross-sectional survey. BMC Complement. Altern. Med. (no pagination), 2014. Article Number 432. Date Publ. 2014;1-8.

58. Kennedy DA, Lupattelli A, Koren G, Nordeng H. Herbal medicine use in pregnancy: results of a multinational study. BMC Complement. Altern Med. 2013;13:355. Available from: http://www.pubmedcentral.nih.gov/ articlerender.fcgi?artid=4029224\&tool=pmcentrez\&rendertype=abstract.

59. M'soka NC, Mabuza LH, Pretorius D. Cultural and health beliefs of pregnant women in Zambia regarding pregnancy and child birth. Curationis. 2015;38:1-7. Available from: http://www.curationis.org.za/index.php/ curationis/article/view/1232.

60. Ngomane S, Mulaudzi FM. Indigenous beliefs and practices that influence the delayed attendance of antenatal clinics by women in the Bohlabelo district in Limpopo, South Africa. Midwifery. Elsevier. 2012;28:30-8. Available from: http://www.sciencedirect.com/science/article/pii/S0266613810001816

\section{Submit your next manuscript to BioMed Central and we will help you at every step:}

- We accept pre-submission inquiries

- Our selector tool helps you to find the most relevant journal

- We provide round the clock customer support

- Convenient online submission

- Thorough peer review

- Inclusion in PubMed and all major indexing services

- Maximum visibility for your research

Submit your manuscript at www.biomedcentral.com/submit
Biomed Central 